\title{
Fetal mesenchymal stem cells ameliorate acute lung injury in a rat cardiopulmonary bypass model
}

Tomofumi Taki, MD, Hidetoshi Masumoto, MD, PhD, Masaki Funamoto, MD, Kenji Minakata, MD, PhD, Kazuhiro Yamazaki, MD, PhD, Tadashi Ikeda, MD, PhD, and Ryuzo Sakata, MD, PhD

\begin{abstract}
Background: Systemic inflammation after prolonged cardiopulmonary bypass (CPB) can cause serious multiorgan system dysfunction. Mesenchymal stem cells (MSCs) are reported to reduce inflammation and attenuate immune response. We have focused on fetal membrane (FM) as a source to provide a large number of MSCs (FM-MSCs). Allogeneic administration of FM-MSCs has been reported to mitigate autoimmune myocarditis or glomerulonephritis. The aim of this study was to investigate whether allogeneic FM-MSCs attenuate systemic inflammatory responses and lung injury in a rat $\mathrm{CPB}$ model.
\end{abstract}

Methods: Male Lewis rats (major histocompatibility complex haplotype: RT-11) were divided randomly into 3 groups $(\mathrm{n}=7$ each): cannulation alone (sham group), CPB alone (control group), and CPB + MSC (MSC group). An experimental rat CPB model was established, and $\mathrm{CPB}$ was maintained for 30 minutes. In the MSC group, MSCs $\left(1 \times 10^{6}\right.$ cells $)$ derived from the FM of ACI rats with a different major histocompatibility complex haplotype (RT-1a) were administrated intravenously before CPB initiation.

Results: Serum concentrations of tumor necrosis factor- $\alpha$, interleukin-6, and interleukin- $1 \beta$ in the MSC group were significantly lower compared with the control group after CPB. Similarly, mRNA expression of proinflammatory cytokines in the lung was lower in the MSC group. Allogeneic administration of FM-MSCs remarkably decreased the lung injury score, protected alveolar structure, inhibited neutrophil infiltration to the lung interstitium, and stimulated cytoprotective cytokine production in the lung.

Conclusions: Allogeneic transplantation of FM-MSCs may be a potent strategy to prevent CPB-induced systemic inflammation and acute lung injury by suppressing the expression of inflammatory cytokines and promoting protective factors in the lung. (J Thorac Cardiovasc Surg 2017;153:726-34)

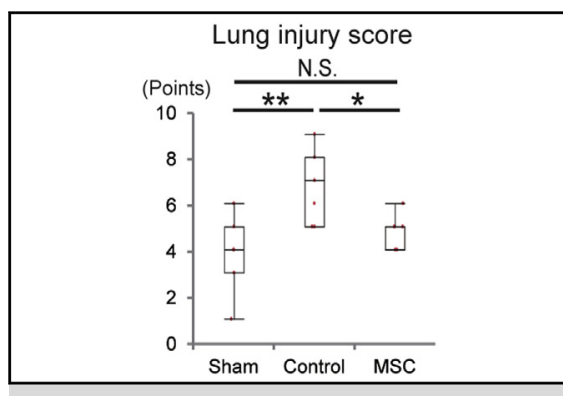

Ameliorated lung injury score after mesenchymal stem cells treatment on a rat cardiopulmonary bypass model.

\section{Central Message}

Allogeneic administration of fetal membranederived mesenchymal stem cells attenuated cardiopulmonary bypass-related rat lung injury.

\section{Perspective}

Administration of allogeneic fetal membranederived mesenchymal stem cells holds potential to become a novel prophylactic strategy for preventing severe systemic inflammatory responses and acute lung injury associated with cardiopulmonary bypass, which can be a lethal complication after cardiac or aortic surgery.

See Editorial Commentary page 735.
Cardiac surgeries with cardiopulmonary bypass (CPB) are known to be associated with severe inflammation that can lead to postoperative complications. A prospective

\footnotetext{
From the Department of Cardiovascular Surgery, Kyoto University Graduate School of Medicine, Kyoto, Japan.

This work was supported by research grants from the Ministry of Health, Labour and Welfare of Japan (to R.S.) and the Invited Research Project of the Institute for Advancement of Clinical and Translational Science, Kyoto University Hospital (to R.S.).

Received for publication May 30, 2016; revisions received Sept 20, 2016; accepted for publication Oct 7, 2016; available ahead of print Nov 9, 2016.

Address for reprints: Hidetoshi Masumoto, MD, PhD, Department of Cardiovascular Surgery, Kyoto University Graduate School of Medicine, 54 Shogoin Kawaharacho, Sakyo-ku, Kyoto 606-8507, Japan (E-mail: masumoto@kuhp.kyoto-u.ac.jp). $0022-5223 / \$ 36.00$

Copyright (c) 2016 by The American Association for Thoracic Surgery http://dx.doi.org/10.1016/j.jtcvs.2016.10.014
}

observational study found that inflammatory cytokines such as tumor necrosis factor- $\alpha$ (TNF- $\alpha$ ) and interleukin (IL)-6 have the potential to serve as predicting factors of organ dysfunction. ${ }^{1}$ In particular, cytokine-mediated acute lung injury is a well-known complication after cardiac surgery, occurring in $2 \%$ to $3 \%$ of patients undergoing $\mathrm{CPB}$, and the resulting mortality has been reported to be $15 \%$ to $50 \%{ }^{2}$ In light of such findings, ways to ameliorate

Scanning this QR code will take you to the article title page. 


$$
\begin{aligned}
& \text { Abbreviations and Acronyms } \\
& \begin{aligned}
\mathrm{BM} & =\text { bone marrow } \\
\mathrm{CPB} & =\text { cardiopulmonary bypass } \\
\mathrm{FM} & =\text { fetal membrane } \\
\mathrm{IL} & =\text { interleukin } \\
\mathrm{KGF} & =\text { keratinocyte growth factor } \\
\mathrm{MHC} & =\text { major histocompatibility complex } \\
\mathrm{MSC} & =\text { mesenchymal stem cells } \\
\mathrm{PCR} & =\text { polymerase chain reaction } \\
\mathrm{TGF} & =\text { transforming growth factor } \\
\mathrm{TNF}-\alpha & =\text { tumor necrosis factor- } \alpha
\end{aligned}
\end{aligned}
$$

acute lung injury after CPB are being investigated actively. $^{3,4}$

Mesenchymal stem cells (MSCs) are multipotent stem cells present in bone marrow (BM), adipose tissue, and many other tissues that can differentiate into a variety of cells, including adipocytes, osteocytes, and chondrocytes. ${ }^{5,6}$ Several studies have reported that transplanted BM-MSCs reduce lung impairment in experimental lung injury models induced by endotoxin, ${ }^{7}$ hemorrhage shock, ${ }^{8}$ or mechanical ventilation. ${ }^{9}$ It is reported that MSCs might attenuate the recruitment of polymorphonuclear neutrophils, which are regarded as one of the key innate immunologic and inflammatory cells, and the release of neutrophil elastase by suppressing the release of early-stage proinflammatory cytokines such as TNF- $\alpha$ and IL-6 in a rat ventilator-induced lung injury model. ${ }^{10}$

Although BM-MSCs hold promising therapeutic potential for the treatment of CPB-associated lung injury, there are limitations for the application of autologous BM-MSCs in clinical situations. BM-procurement procedures in humans are invasive, including such techniques as BM puncture, ${ }^{11}$ and may yield relatively low numbers of MSCs after processing. ${ }^{12,13}$ An alternative source of MSCs that would yield larger quantities of cells via a less-invasive method is desirable. With this in mind, we focused on fetal membrane (FM), a remnant after birth that normally is discarded after delivery. Several studies have reported that human FM contains multipotent cells similar to BM-MSCs, ${ }^{14,15}$ and this led us to believe that FM may be a good source of MSCs. It was reported previously that the allogeneic transplantation of FM-derived MSCs (FM-MSCs) induced therapeutic angiogenesis in a rat hind-limb ischemia model comparable with the effect induced by BM-MSCs. ${ }^{16}$ Furthermore, it is reported that the allogeneic administration of FM-MSCs attenuated autoimmune myocarditis ${ }^{17}$ and glomerulonephritis. ${ }^{18}$ In an experimental autoimmune myocarditis model, it is demonstrated that the administration of
FM-MSC suppressed T-helper 1/T-helper 17 immunity and macrophage infiltration in myocarditis tissue, which led to improved cardiac function. ${ }^{19}$

In this study, we investigated whether the intravenous injection of allogeneic FM-MSCs attenuates systemic inflammation and acute lung injury induced by CPB and the mechanisms underlying this potential organ-protective effect.

\section{METHODS}

\section{Animals}

Experimental protocols were approved by the Ethics Review Committee for Animal Experimentation of Kyoto University Graduate School of Medicine. All animals received humane care in compliance with the guidelines prescribed in the Principles of Laboratory Animal Care, formulated by the National Society for Medical Research, and the Guide for the Care and Use of Laboratory Animals, created by the Institute of Laboratory Animal Resources of the National Research Council and published by the National Academies Press (revised 2011).

Different strains of rats were used according to their major histocompatibility complex (MHC) antigen disparity: Lewis (MHC haplotype: RT-11) and ACI (MHC haplotype: RT-1a) rats (Japan SLC, Hamamatsu, Japan).

\section{Preparation of FM-MSCs}

Rat FM-MSCs generously were gifted from National Cerebral and Cardiovascular Center, Suita, Japan. The isolation and expansion of rat FM-MSCs were performed as described previously. ${ }^{16-19}$ In brief, FM was obtained from pregnant ACI rats on day 15 after conception. Minced FM was digested with type II collagenase solution $(300 \mathrm{U} / \mathrm{mL}$; Worthington Biochemicals, Lakewood, NJ) for 1 hour at $37^{\circ} \mathrm{C}$. After filtration and centrifugation, FM-derived cells were suspended in $\alpha$-MEM (Invitrogen Corp, Carlsbad, Calif) supplemented with $10 \%$ fetal bovine serum (Invitrogen) and 1\% penicillin/streptomycin (Invitrogen), and cultured in standard plastic dishes. The adherent MSC populations appeared by day 5 to 7 , and these FM-MSCs were used for 5 to 7 passages.

\section{Experimental Groups}

Male Lewis rats were divided randomly into the following 3 experimental groups ( $\mathrm{n}=7$ per group): animals undergoing only cannulation (sham group); animals undergoing CPB and PBS injection (control group); and animals undergoing CPB and FM-MSC administration obtained from ACI rats (MSC group).

\section{Surgical Preparation and CPB}

Lewis rats were anesthetized with $3 \%$ isoflurane in air and intubated with a 16-gauge catheter as a tracheal tube. Mechanical ventilation was adjusted to maintain a $\mathrm{PaCO}_{2}$ of 30 to $40 \mathrm{~mm} \mathrm{Hg}$, and general anesthesia was maintained with $1.5 \%$ to $2.0 \%$ isoflurane inhalation. The right femoral artery was cannulated with a 24-gauge catheter for arterial pressure monitoring and blood sampling. After an intra-arterial injection of 200 IU heparin, the left femoral artery was cannulated with a 24-gauge catheter for arterial inflow. A multiorifice 17-gauge cannula was advanced through the right jugular vein into the right atrium for venous drainage. The CPB circuit consisted of a venous reservoir, a roller pump, a heat exchanger, and a custom-designed membrane oxygenator.

The circuit was primed with $11.2 \mathrm{~mL}$ of solution consisting of lactated Ringer's solution $(10.5 \mathrm{~mL})$, sodium bicarbonate $(0.5 \mathrm{~mL})$, and heparin $(0.2 \mathrm{~mL})$. The rectal temperature of the rats was maintained within a range of $36^{\circ} \mathrm{C}$ to $37^{\circ} \mathrm{C}$ by placing them on an electrical heater throughout the procedure. In the MSC group, $0.2 \mathrm{~mL}$ of phosphate-buffered saline containing MSCs $\left(1 \times 10^{6}\right.$ cells $)$ derived from FM of ACI rats was injected before 
CPB initiation intravenously. The control group received $0.2 \mathrm{~mL}$ of phosphate-buffered saline only. The flow rate was kept to $50 \mathrm{~mL} / \mathrm{kg} / \mathrm{min}$ (half flow) and maintained for 30 minutes. During CPB, mechanical ventilation was kept to minimum frequency of breathing (3-5/min) for avoiding atelectasis. One hour after CPB termination, blood samples were collected for assessment of systemic inflammatory response, and the lung were harvested for the examination of local inflammation and histology.

\section{Enzyme-Linked Immunosorbent Assay}

Serum protein concentrations of TNF- $\alpha$, IL-6, IL- $1 \beta$, and IL-10 were quantified by enzyme-linked immunosorbent assay according to the manufacturer's instructions (R\&D Systems, Minneapolis, Minn).

\section{Quantitative Real-Time Polymerase Chain Reaction (PCR)}

Total RNA was isolated from the right upper lobe of the lung with an RNeasy Mini Kit (QIAGEN, Hilden, Germany) and reverse-transcribed with the use of Omniscript Reverse transcriptase (QIAGEN). Gene-specific primers for rat TNF- $\alpha$ (TaqMan, Tnf; Rn01525859_g1), IL-6 (TaqMan, Il6; Rn01410330_m1), IL-1 $\beta$ (TaqMan, Il1b; Rn00580432_m1), keratinocyte growth factor (KGF; TaqMan, Fgf7; Rn00573319_m1), transforming growth factor (TGF)- $\beta$ (TaqMan, Tgfb; Rn00572010_m1), and glyceraldehyde-3-phosphate dehydrogene (TaqMan, Gapdh; Rn01775763_g1) were purchased from Applied Biosystems (Foster City, Calif). Quantitative realtime PCR was performed with Power SYBR Green PCR Master Mix (Applied Biosystems) and the StepOne Plus system (Applied Biosystems) with the indicated primers. The expression of each mRNA was normalized to that of glyceraldehyde-3-phosphate dehydrogene.

\section{Histological Assessments}

Lung samples were fixed with $10 \%$ formalin and embedded in paraffin, and $4-\mu \mathrm{m}$ sections were stained with hematoxylin and eosin. A digital microscope and analyzing software (Biorevo BZ 9000; Keyence, Osaka, Japan) was used to automatically measure the alveolar and interstitial area, and alveolar airspace ratio was calculated to evaluate the structural integrity of alveolar tissue.

Lung sections also were stained with polyclonal rabbit anti-human myeloperoxidase antibody (Dako, Glostrup, Denmark) to count the number of infiltrated interstitial neutrophils. All images were photographed and analyzed with a digital microscope and analyzing software (Biorevo BZ 9000; Keyence). In all histologic assessments, 20 fields per section were selected randomly and examined by an experienced pathologist (F. Kataoka) blinded to treatment.

\section{Semiquantitative Histologic Grading Criteria for Lung Injury Score}

The histologic findings were evaluated by the use of the modified semiquantitative scores reported by $\mathrm{Su}$ and colleagues. ${ }^{20}$ Briefly, lung injury was evaluated using the sum of the scores for the following 5 factors: interstitial edema, hemorrhage, neutrophil infiltration, atelectasis, and necrosis. Each score of microscopic injury was determined according to the following scoring criteria: 0 , normal; 1 , minimal $(<25 \%)$; 2 , mild $(25 \%$ $50 \%) ; 3$, moderate $(50 \%-75 \%)$; and 4 , severe $(>75 \%)$. Greater sum scores indicated more severe lung injury.

\section{Statistical Analysis}

All data are expressed as mean \pm standard deviation. Statistical analysis was performed with SPSS for Windows v21 (IBM Corp, Armonk, NY). Comparisons between 2 parameters were analyzed with the unpaired Student $t$ test. Comparisons of parameters among the 3 groups were made by one-way analysis of variance followed by the Tukey test. A value of $P<.05$ was considered statistically significant.
TABLE 1. Physiological data during the surgical procedure

\begin{tabular}{|c|c|c|c|}
\hline Group & Pre-CPB & During CPB & Post-CPB \\
\hline \multicolumn{4}{|c|}{ MAP, $\mathrm{mm} \mathrm{Hg}$} \\
\hline Sham & $76.4 \pm 4.2$ & $65.1 \pm 5.3$ & $75.3 \pm 5.7$ \\
\hline Control & $66.6 \pm 1.7$ & $59.4 \pm 2.1$ & $73.4 \pm 4.1$ \\
\hline MSC & $73.9 \pm 6.1$ & $55.0 \pm 1.8$ & $72.0 \pm 4.0$ \\
\hline \multicolumn{4}{|l|}{$\mathrm{pH}$} \\
\hline Sham & $7.48 \pm 0.02$ & $7.48 \pm 0.01$ & $7.48 \pm 0.01$ \\
\hline Control & $7.53 \pm 0.02$ & $7.50 \pm 0.01$ & $7.52 \pm 0.02$ \\
\hline MSC & $7.53 \pm 0.02$ & $7.51 \pm 0.01$ & $7.50 \pm 0.01$ \\
\hline \multicolumn{4}{|c|}{$\mathrm{PaCO}_{2}, \mathrm{~mm} \mathrm{Hg}$} \\
\hline Sham & $33.6 \pm 3.5$ & $31.2 \pm 1.8$ & $35.6 \pm 0.9$ \\
\hline Control & $31.0 \pm 2.7$ & $30.7 \pm 1.5$ & $34.5 \pm 1.6$ \\
\hline MSC & $31.3 \pm 2.3$ & $29.8 \pm 2.5$ & $34.8 \pm 1.3$ \\
\hline \multicolumn{4}{|c|}{$\mathrm{PaO}_{2}, \mathrm{~mm} \mathrm{Hg}$} \\
\hline Sham & $85.9 \pm 7.5$ & $98.8 \pm 14.1$ & $104.6 \pm 11.7$ \\
\hline Control & $83.4 \pm 12.5$ & $332.0 \pm 32.1 *$ & $111.6 \pm 7.8$ \\
\hline MSC & $83.9 \pm 8.8$ & $321.7 \pm 45.8^{*}$ & $120.6 \pm 7.3$ \\
\hline \multicolumn{4}{|c|}{ Hematocrit, \% } \\
\hline Sham & $39.0 \pm 1.1$ & $35.4 \pm 0.6$ & $33.9 \pm 0.9$ \\
\hline Control & $40.1 \pm 0.6$ & $14.7 \pm 0.5^{*}$ & $21.7 \pm 0.5^{*}$ \\
\hline MSC & $38.4 \pm 0.7$ & $14.3 \pm 0.4^{*}$ & $21.6 \pm 1.0^{*}$ \\
\hline \multicolumn{4}{|c|}{ Heart rate, bpm } \\
\hline Sham & $330 \pm 56$ & $314 \pm 64$ & $406 \pm 28$ \\
\hline Control & $343 \pm 26$ & $316 \pm 34$ & $426 \pm 32$ \\
\hline MSC & $342 \pm 33$ & $303 \pm 35$ & $420 \pm 24$ \\
\hline \multicolumn{4}{|c|}{ Rectal temperature, ${ }^{\circ} \mathrm{C}$} \\
\hline Sham & $36.2 \pm 0.8$ & $36.5 \pm 1.3$ & $37.0 \pm 0.4$ \\
\hline Control & $36.3 \pm 0.7$ & $35.0 \pm 1.0$ & $36.9 \pm 0.7$ \\
\hline MSC & $36.0 \pm 1.0$ & $36.1 \pm 1.1$ & $37.0 \pm 0.2$ \\
\hline \multicolumn{4}{|c|}{ Lactate, $\mathrm{mmol} / \mathrm{L}$} \\
\hline Sham & $2.0 \pm 0.8$ & $2.5 \pm 1.2$ & $2.6 \pm 1.0$ \\
\hline Control & $2.3 \pm 0.9$ & $7.3 \pm 1.8 \dagger$ & $3.9 \pm 2.0$ \\
\hline MSC & $1.7 \pm 0.4$ & $7.0 \pm 1.7 \dagger$ & $2.7 \pm 0.7$ \\
\hline \multicolumn{4}{|c|}{ Base excess, $\mathrm{mmol} / \mathrm{L}$} \\
\hline Sham & $0.2 \pm 1.7$ & $1.3 \pm 2.9$ & $-0.7 \pm 2.2$ \\
\hline Control & $1.0 \pm 2.9$ & $-3.4 \pm 1.6 \dagger$ & $2.2 \pm 1.6^{*}$ \\
\hline MSC & $1.7 \pm 2.8$ & $-2.5 \pm 2.2^{*}$ & $3.9 \pm 1.7 \dagger$ \\
\hline
\end{tabular}

Each variable was obtained before $\mathrm{CPB}$ (pre-CPB), at 15 minutes after initiation of $\mathrm{CPB}$ (during- $\mathrm{CPB}$ ), and 1 hour after termination of $\mathrm{CPB}$ (post-CPB), $\mathrm{N}=$ 7. $C P B$, Cardiopulmonary bypass; $M A P$, mean arterial pressure; $M S C$, mesenchymal stem cells. ${ }^{*} P<.05, \dagger P<.01$ compared with the sham group.

\section{RESULTS}

\section{Physiological Data Throughout CPB}

All rats survived for at least 1 hour after the CPB procedure. Physiological parameters during surgery are shown in Table 1. Throughout the CPB experiment, there were no significant differences between the groups in mean arterial pressure; however, partial oxygen pressure was highly elevated in both the control group and the MSC group after initiation of $\mathrm{CPB}$, indicating successful induction of $\mathrm{CPB}$ with stable hemodynamics in both groups. The hematocrit in the control group and the MSC group decreased during $\mathrm{CPB}$ and post-CPB compared with the sham group, indicating hemodilution after $\mathrm{CPB}(P<.01$ each). 


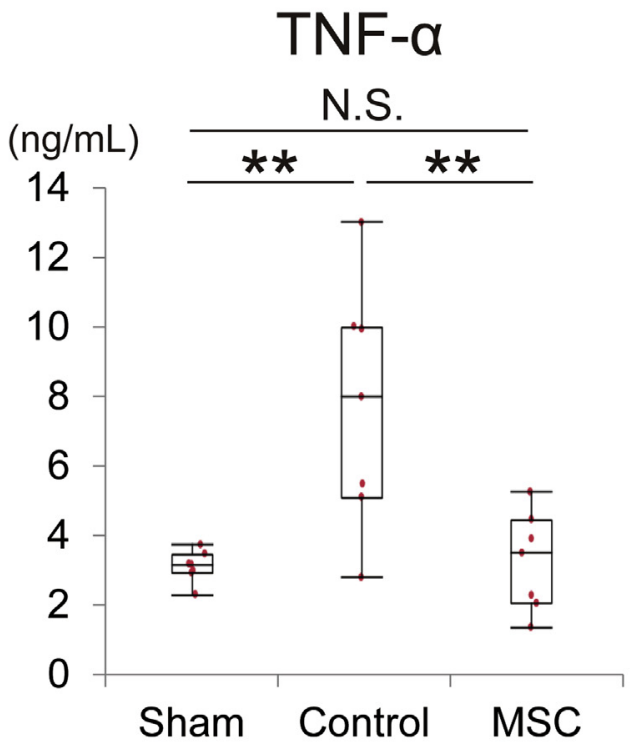

A

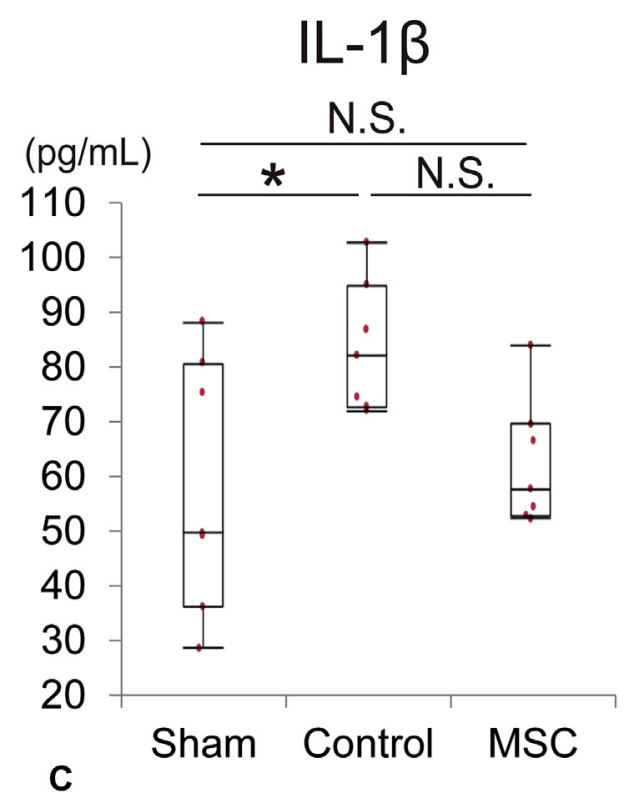

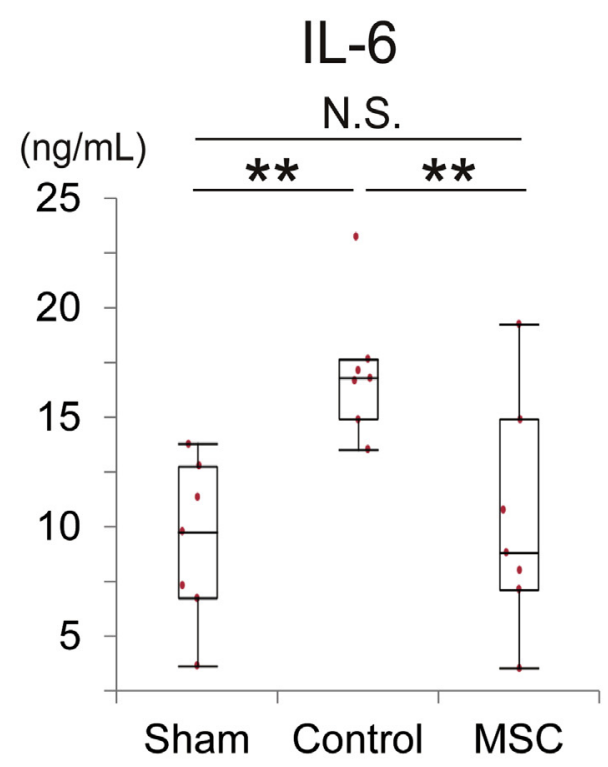

B

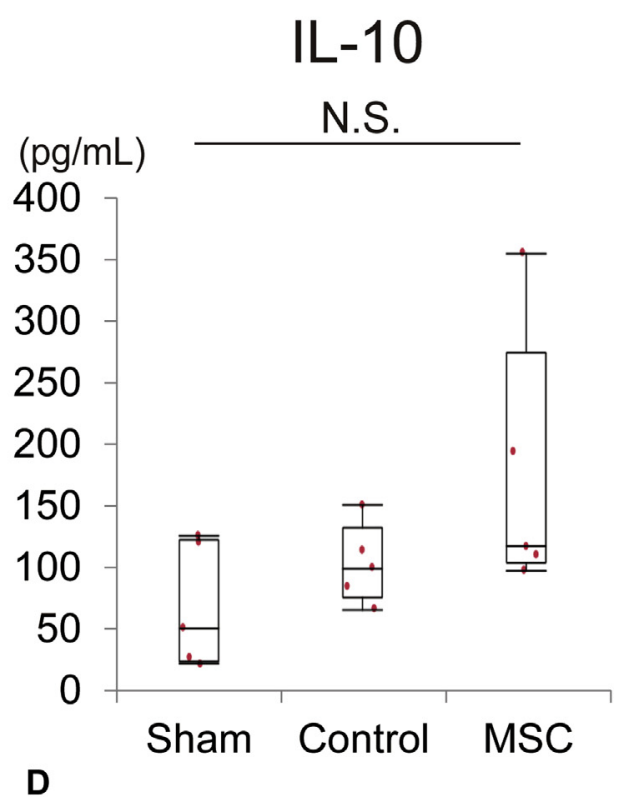

FIGURE 1. Inflammatory cytokine levels in serum after CPB. ELISA, $\mathrm{n}=7$. A, TNF- $\alpha$; B, IL-6; C, IL-1 $\beta$; D, IL-10. *P<.05, **P<.01. TNF- $\alpha$, Tumor necrosis factor- $\alpha$; N.S., not significant; $M S C$, mesenchymal stem cells; $I L-6$, interleukin-6; $I L-1 \beta$, interleukin-1 $\beta ; I L-10$, interleukin- 10 .

\section{FM-MSCs Mitigated Exacerbation of Inflammatory Cytokine Levels After CPB}

One hour after CPB termination, serum concentrations of inflammatory cytokines such as TNF- $\alpha$, IL-6, and IL- $1 \beta$ were significantly elevated in the control group compared with the sham group (sham group vs control group; TNF- $\alpha: 3.03 \pm 0.45$ vs $7.68 \pm 3.52 \mathrm{ng} / \mathrm{mL}, P=.003$; IL-6: $9.30 \pm 3.62$ vs $17.07 \pm 3.04 \mathrm{ng} / \mathrm{mL}, P=.006$; IL-1 $\beta: 58.1 \pm 23.1$ vs $83.5 \pm 11.8 \mathrm{pg} / \mathrm{mL}, P=.03$; Figure $1, A-C$ ). In MSC group, the concentrations of
TNF- $\alpha$ and IL-6 were significantly lower (MSC group; TNF- $\alpha$ : $3.18 \pm 1.41 \mathrm{ng} / \mathrm{mL}, \quad P=.003$; IL-6: $10.30 \pm 5.22 \mathrm{ng} / \mathrm{mL}, P<.01$; vs control group) and IL-1 $\beta$ concentration was tend to be lower (MSC group; $62.3 \pm 11.6 \mathrm{pg} / \mathrm{m}, P=.06 \mathrm{vs}$ control group) than those in the control group (not significant). These concentrations were similar to those observed in the sham group (Figure 1, $A-C$ ). Concentration of IL-10, a cytokine known to suppress inflammatory reactions, showed a tendency toward increase in the MSC group compared with the 

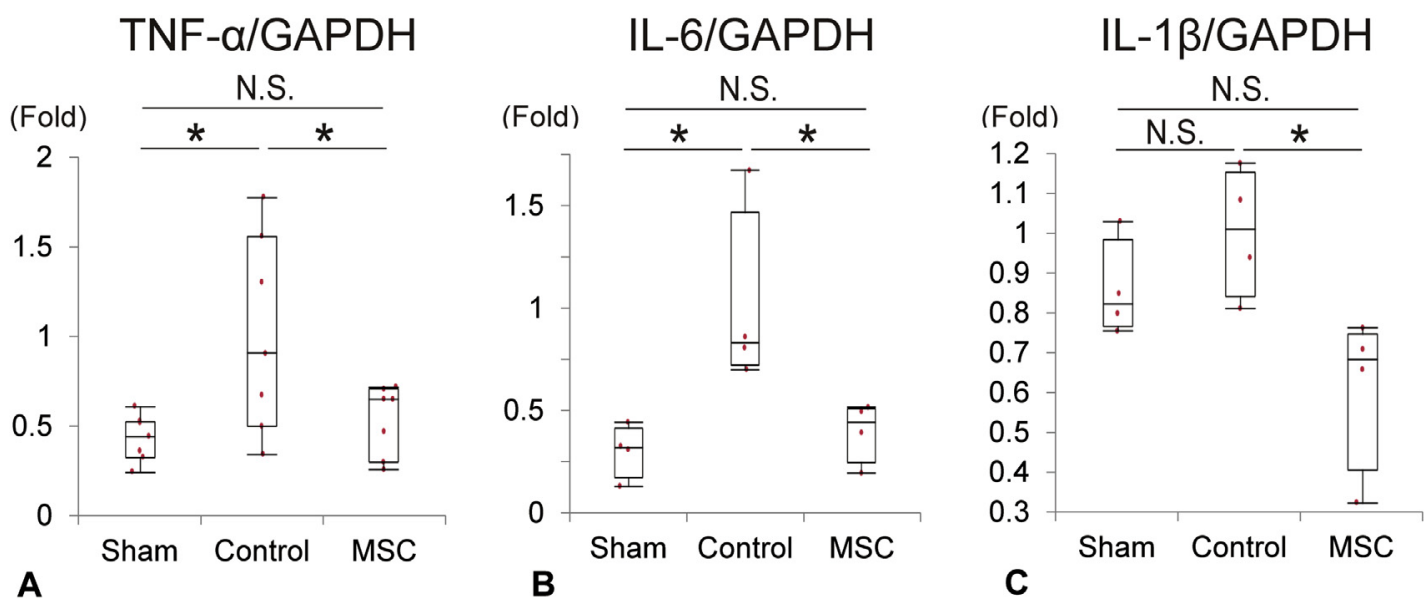

FIGURE 2. Inflammatory cytokine levels in the lung after CPB. qRT-PCR, $\mathrm{n}=4$ to 7 . A, TNF- $\alpha$; B, IL-6; C, IL- $1 \beta$. *P<.05. TNF- $\alpha$, Tumor necrosis factor- $\alpha$; GAPDH, glyceraldehyde 3-phosphate dehydrogenase; N.S., not significant; $M S C$, mesenchymal stem cells; $I L-6$, interleukin-6; $I L-1 \beta$, interleukin- $1 \beta$.

sham group and the control group $(P=.09$ : analysis of variance; Figure $1, D)$.

Next, we examined local expression levels of inflammatory cytokines in the lung. Quantitative real-time PCR revealed that the expression levels of TNF- $\alpha$, IL- 6 , and IL- $1 \beta$ in the lung were significantly lower in the MSC group compared with the control group (TNF- $\alpha$ : $0.53 \pm 0.19$-fold vs the control group, $P=.048$; IL-6: $0.39 \pm 0.15$-fold vs the control group, $P=.03$; IL- $1 \beta$ : $0.61 \pm 0.20$-fold vs the control group, $P=.02$; Figure $2, A-C$ ).

\section{FM-MSCs Attenuated Pathologic Changes in the Lung After CPB}

Microscopic findings in the lungs of the control group showed severe inflammatory changes induced by $\mathrm{CPB}$, including alveolar structural destruction, interstitial edema, and infiltration of neutrophils (Figure $3, A$ and $B$ ). Neutrophil infiltration to the interstitial space of the lung was significantly lower in the MSC group compared with the control group (sham group vs control group vs MSC group; $23.2 \pm 7.8$ vs $40.3 \pm 5.3$ vs $28.3 \pm 4.9$ cells, $P=.03$ in the control vs MSC; Figure 3, B). According to semiquantitative grading, ${ }^{20,21}$ the lung injury score was significantly lower in MSC group compared with those in the control group (control group vs MSC group; $6.9 \pm 1.6$ vs $4.7 \pm 0.8, P=.02$; Figure $3, C$ ). As shown in Figure 3, $C$, alveolar airspace ratio in the MSC group was significantly greater than in the control group (control group vs MSC group; $43.2 \pm 3.3 \%$ vs $55.1 \pm 3.6 \%, P=.004$ ) (Figure $3, D$ ).

\section{FM-MSCs Accelerated Local Production of Protective Factors Against Alveolar Damage}

In the MSC group, the expression of KGF and TGF- $\beta 1$ in the lung, which are known as protective factors against alveolar damage, was remarkably greater compared with the control group (KGF: $1.22 \pm 0.16$-fold vs the control group, $P=.03$; TGF- $\beta 1$ : $1.31 \pm 0.25$-fold vs the control group, $P=.045$; Figure 4 ).

\section{DISCUSSION}

In the present study, we interpreted the results of the present study as intravenous administration of allogeneic FM-MSCs attenuated systemic inflammation and lung injury after CPB in a rat model. In our experimental model, administrated FM-MSCs did the following: (1) suppressed the production of proinflammatory cytokines, (2) alleviated acute lung injury, (3) inhibited neutrophil infiltration to interstitial spaces of the lung, and (4) protected alveolar structure by stimulating secretion of organ-protective humoral factors.

In the clinical setting of cardiac surgery, prolonged $\mathrm{CPB}$ can induce acute lung injury or acute respiratory distress syndrome by various mechanisms such as inflammatory responses, lung ischemia, atelectasis, blood transfusion. ${ }^{3}$ Even though we could not conduct hypothermic CPB in the present study, the level of increases in inflammatory cytokines in the present study was almost comparable with those reported in other inflammatory conditions such as sepsis, ${ }^{22,23}$ indicating that we could induce severe inflammatory status associated with clinical prolonged CPB. In recent decades, the basic mechanisms underlying CPB-induced inflammation and organ dysfunction largely have been elucidated. ${ }^{24,25}$ Especially, it is crucial to investigate CPB-related lung complications in patients with severe chronic obstructive pulmonary disease, and we may apply our current system to chronic obstructive pulmonary disease or emphysema models in the future. Several pharmaceutical strategies to attenuate the inflammatory cascade involved in CPB-induced lung injury have been studied, 

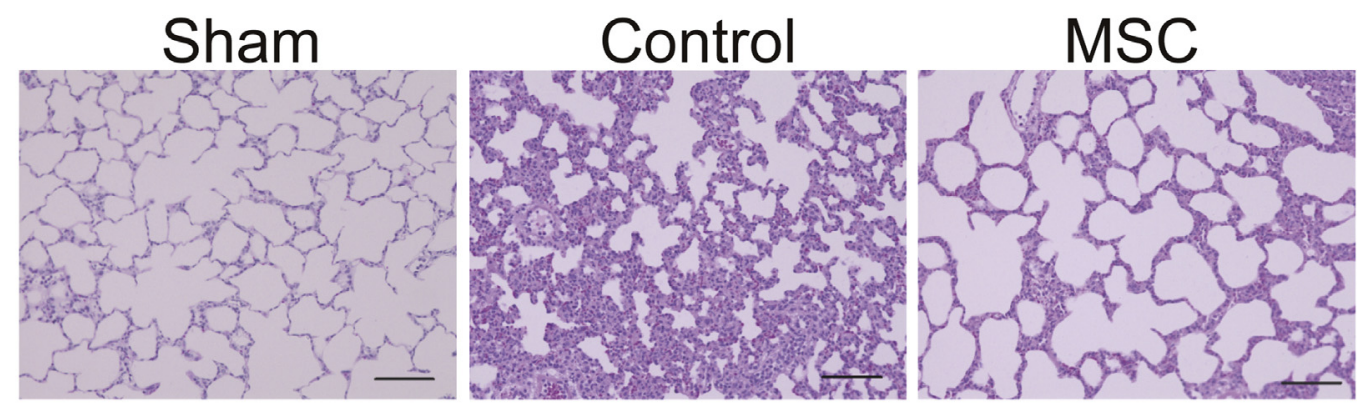

A

Sham

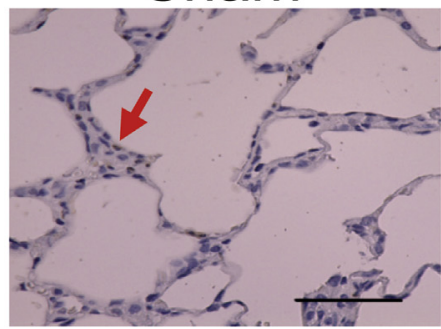

B
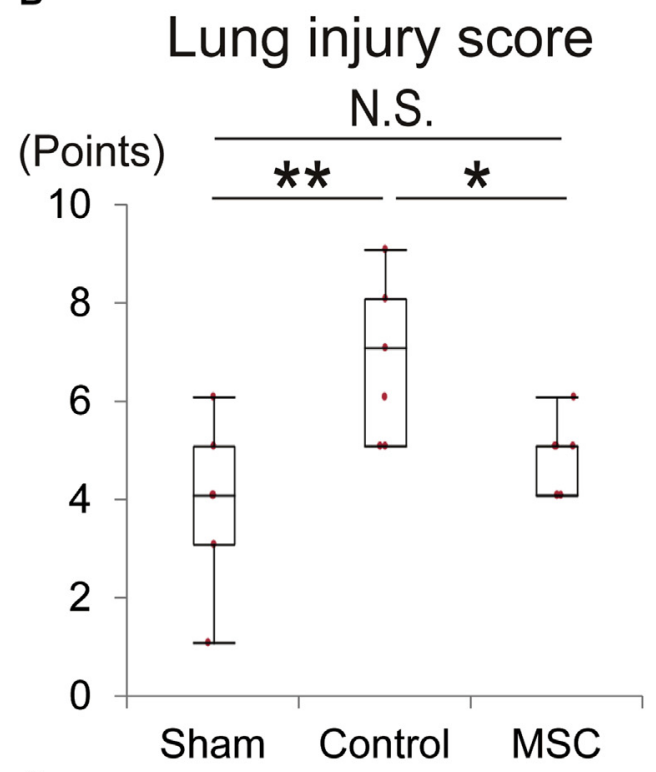

Control

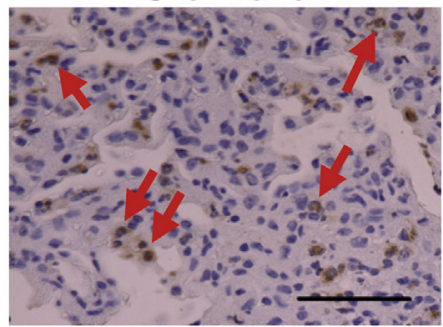

MSC

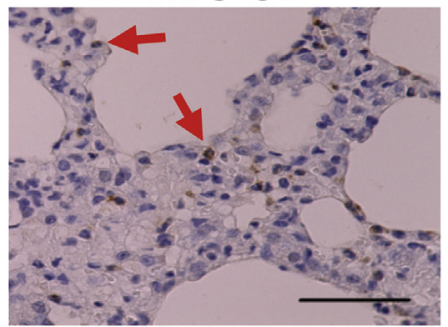

Alveolar space ratio

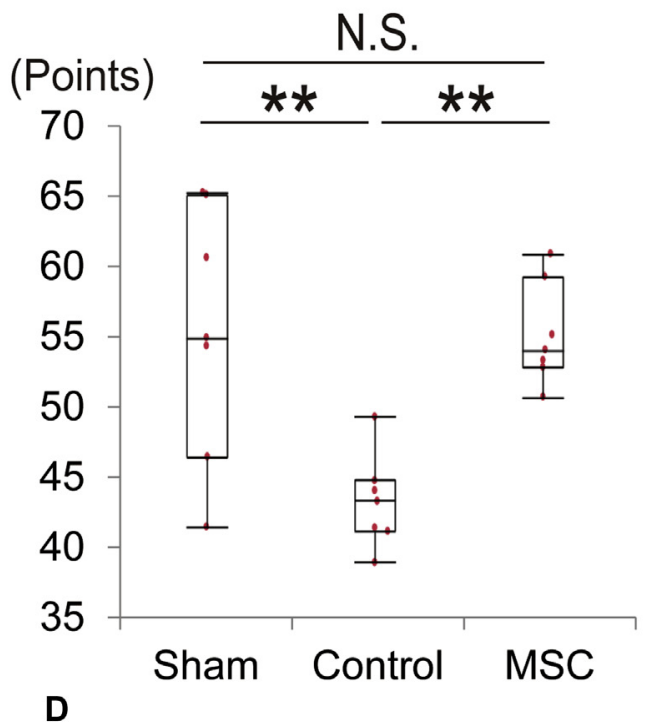

FIGURE 3. Histopathologic analysis of lung tissue after $\mathrm{CPB}, \mathrm{n}=7$. A, Hematoxylin and eosin staining, scale bars $=50 \mu \mathrm{m}$. B, Peroxidase staining for neutrophils (brown). Arrows: neutrophils. Scale bars $=50 \mu \mathrm{m}$. C, Lung injury score, $\mathrm{n}=7$. D, Alveolar space ratio, $\mathrm{n}=7$. $* P<.05, * * P<.01$. MSC, Mesenchymal stem cells; N.S., not significant.

such as corticosteroids, statins, and angiotensin-converting enzyme inhibitors, but the mechanisms by which these drugs reduce postoperative complications remain unclear. ${ }^{26}$

MSCs are considered an attractive cell source for regenerative medicine because of their excellent capacity for proliferation and differentiation. ${ }^{27-29}$ A considerable number of clinical trials using MSCs have been conducted targeting various disorders, including acute myocardial infarction, ${ }^{30}$ ischemic heart failure, ${ }^{31,32}$ graft versus host disease, ${ }^{33}$ inflammatory bowel disease, ${ }^{34}$ and respiratory disease. ${ }^{35}$ Several studies that have used experimental animal models of lung injury induced by lipopolysaccharides, ${ }^{7}$ bleomycin, ${ }^{36}$ artificial ventilation, ${ }^{9}$ and hemorrhage shock ${ }^{8}$ generally have demonstrated that MSCs attenuate the production of inflammatory cytokines and reduce edema and neutrophil recruitment. 


\section{KGF/GAPDH}

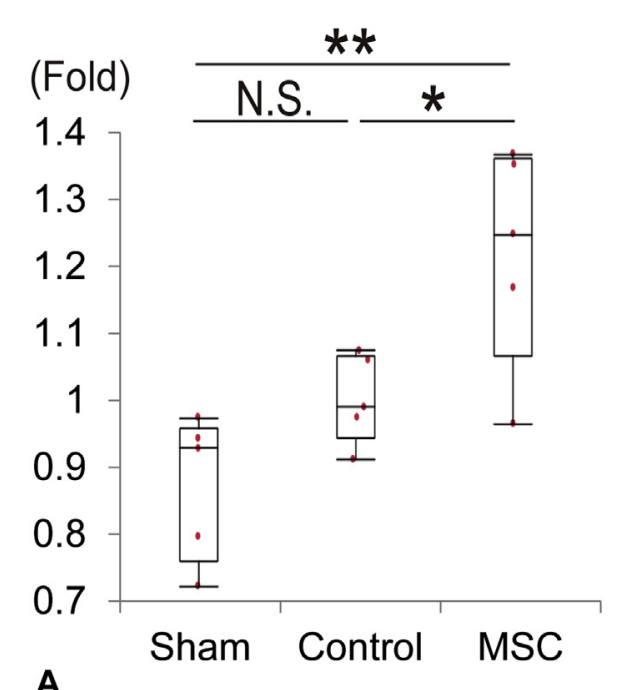

\section{TGF- $\beta 1 / G A P D H$}

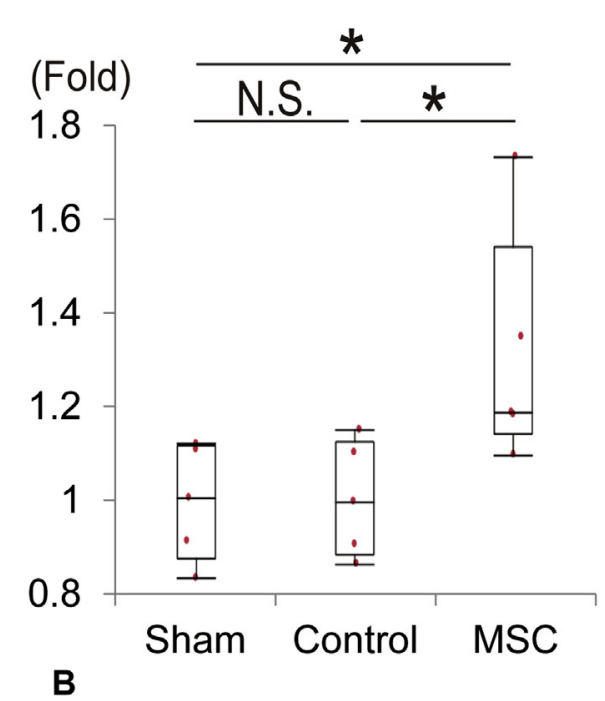

FIGURE 4. Cytoprotective cytokine levels in the lung after CPB. qRT-PCR, $\mathrm{n}=5$. A, KGF; B, TGF- $\beta 1 . * P<.05$, ** $P<.01$. KGF, Keratinocyte growth factor; GAPDH, glyceraldehyde 3-phosphate dehydrogenase; N.S., not significant; $T G F$ - $\beta 1$, transforming growth factor- $\beta 1$.

To date, most MSC-related clinical studies have used cells originating from BM; however, BM aspiration has several limitations, including invasiveness, relatively small acquired cell numbers, and donorsite morbidity. ${ }^{11}$ It was reported previously that MSCs from FM tissue possess great advantages due to their abundance and easy accessibility. ${ }^{19}$ It also was reported that intravenous administration of FM-MSCs ameliorated cardiac dysfunction in a rat autoimmune myocarditis model ${ }^{17}$ and renal function in a rat glomerulonephritis model. ${ }^{18}$ In the present study, we showed that allogeneic administration of FM-MSCs reduced the production of inflammatory cytokines, preserved alveolar structure, and attenuated pulmonary neutrophil infiltration in rat lungs following CPB. To the best of our knowledge, this is the first study to demonstrate that the administration of FM-MSCs protects against CPB-induced lung complications.

Considering broader application of this approach, we conducted an allogeneic treatment using different strain between host and graft, which resulted in effective attenuation of lung injury, indicating immunomodulation of FM-MSCs. A previous report in which the authors used a heart transplantation mouse model with intravenous injection of MSCs showed no difference between the syngeneic and allogenic origin of MSCs in the amount of engraftment and organ distribution of cells. ${ }^{37}$ This report and our present study may indicate that the difference in MSC origin (syngeneic or allogeneic) may not so much affect the host's immune system; however, we should conduct a longer-term experiment to exactly show the immunologic compatibility, and it also should be validated in clinical studies in the future.

The mechanisms that underlie the protective effects of MSCs in the lungs are thought to be multifactorial. Two groups have reported that the protective effects can be attributed to paracrine effects mediated by humoral factors. $^{38,39}$ Another study indicated that MSCs may reduce lung injury and promote tissue repair through interaction with injured alveolar epithelial or lung endothelial cells or by modulating the response of inflammatory cells (neutrophils, macrophages and lymphocytes) and by releasing cytoprotective and tissuereparative factors such as $\mathrm{KGF}$ and TGF- $\beta .^{35} \mathrm{Li}$ and colleagues $^{40}$ reported that BM-MSC administration enhanced recovery after rat lipopolysaccharide-induced acute lung injury and speculated that this might be due to secretion of KGF, which promotes the alveolar fluid clearance of alveolar type-II cells. Just and colleagues ${ }^{41}$ reported that KGF reduced the expression of intercellular adhesion molecule- 1 and vascular cell adhesion molecule1 in bronchial epithelial cells, which would attenuate neutrophil infiltration into interstitial spaces during the lung inflammatory reaction. In the present study, administration of FM-MSCs remarkably decreased the expression of KGF and TGB- $\beta$ in the rat lung. This finding indicates that FM-MSCs might stimulate the secretion of cytoprotective factors in the lung, which can protect alveolar epithelial cells and lung endothelial cells after CPB. It should be 
further investigated that intravenous or intratracheal administration of MSCs may affect to the efficiency of lung repair.

\section{Limitations}

First, we only provided data on serum concentrations 1 hour after termination of CPB. According to our preliminary studies, serum concentrations of pro- and anti-inflammatory cytokines at 24 hours after CPB termination had returned to pre-CPB baselines (data not shown). On the basis of these preliminary results, we speculated that the peak of systemic inflammation due to $\mathrm{CPB}$ in our rat $\mathrm{CPB}$ model would be much less than 24 hours after termination of CPB and set the sample point at 1 hour after CPB termination; however, performing serial measurements of cytokine expressions is required to conclude that the cytokine increase was attributed to FM-MSC administration. It is our future work.

Second, our data did not exclude any potential contribution of other mediators induced by FM-MSCs that contributed to lung repair or protection. Furthermore, we did not compare the results yielded by FM-MSCs to the effects yielded by MSCs derived from BM or adipose tissue. These points should be investigated in the future. The MSCs used were characterized with several cell-specific markers, as previously reported $^{16,17}$; however, we have not checked the marker expression of FM-MSCs used just before infusion. Although the cellular population must not be changed before and after thawing because we just thawed and used them immediately, we cannot completely certify that there was no change of the characteristics of the FM-MSCs.

\section{CONCLUSIONS}

In conclusion, interpreting our results in the present study, we successfully showed that intravenous administration of allogeneic FM-MSCs attenuated systemic inflammation and lung injury following CPB in a rat model. This effect appears to be due to suppression of proinflammatory cytokines and protection of alveolar structures through secretion of cytoprotective factors. Although further studies are needed to apply these results to clinical treatment, allogeneic FM-MSC therapy may be an innovative approach for the prevention of severe pulmonary complications after $\mathrm{CPB}$.

\section{Conflict of Interest Statement}

Authors have nothing to disclose with regard to commercial support.

The authors thank Dr K. Yamahara and Dr T. Ikeda (National Cerebral and Cardiovascular Center, Suita, Japan) for providing rat FM-MSCs; Dr Shiro Tanaka (Kyoto University, Kyoto, Japan) for statistical assistance; Mrs F. Kataoka (Kyoto University) for the technical support; and Mr C. Rowthorn for critical reading of this manuscript.

\section{References}

1. de Mendonca-Filho HT, Pereira KC, Fontes M, Vieira DA, de Mendonca ML, Campos LA, et al. Circulating inflammatory mediators and organ dysfunction after cardiovascular surgery with cardiopulmonary bypass: a prospective observational study. Crit Care. 2006;10:R46.

2. Milot J, Perron J, Lacasse Y, Letourneau L, Cartier PC, Maltais F. Incidence and predictors of ARDS after cardiac surgery. Chest. 2001;119:884-8.

3. Huffmyer JL, Groves DS. Pulmonary complications of cardiopulmonary bypass. Best Pract Res Clin Anaesthesiol. 2015;29:163-75.

4. Yamazaki S, Inamori S, Nakatani T, Suga M. Activated protein C attenuates cardiopulmonary bypass-induced acute lung injury through the regulation of neutrophil activation. J Thorac Cardiovasc Surg. 2011;141:1246-52.

5. Chamberlain G, Fox J, Ashton B, Middleton J. Concise review: mesenchymal stem cells: their phenotype, differentiation capacity, immunological features, and potential for homing. Stem Cells. 2007;25:2739-49.

6. Pittenger MF, Mackay AM, Beck SC, Jaiswal RK, Douglas R, Mosca JD, et al. Multilineage potential of adult human mesenchymal stem cells. Science. 1999; 284:143-7.

7. Liang ZX, Sun JP, Wang P, Tian Q, Yang Z, Chen LA. Bone marrow-derived mesenchymal stem cells protect rats from endotoxin-induced acute lung injury. Chin Med J (Engl). 2011;124:2715-22.

8. Pati S, Gerber MH, Menge TD, Wataha KA, Zhao Y, Baumgartner JA, et al. Bone marrow derived mesenchymal stem cells inhibit inflammation and preserve vascular endothelial integrity in the lungs after hemorrhagic shock. PLoS One. 2011;6:e25171.

9. Curley GF, Hayes M, Ansari B, Shaw G, Ryan A, Barry F, et al. Mesenchymal stem cells enhance recovery and repair following ventilator-induced lung injury in the rat. Thorax. 2012;67:496-501.

10. Lai TS, Wang ZH, Cai SX. Mesenchymal stem cell attenuates neutrophilpredominant inflammation and acute lung injury in an in vivo rat model of ventilator-induced lung injury. Chin Med J (Engl). 2015;128:361-7.

11. Bosi A, Bartolozzi B. Safety of bone marrow stem cell donation: a review. Transplant Proc. 2010;42:2192-4.

12. Dimmeler S, Burchfield J, Zeiher AM. Cell-based therapy of myocardial infarction. Arterioscler Thromb Vasc Biol. 2008;28:208-16.

13. Chen SL, Fang WW, Ye F, Liu YH, Qian J, Shan SJ, et al. Effect on left ventricular function of intracoronary transplantation of autologous bone marrow mesenchymal stem cell in patients with acute myocardial infarction. Am J Cardiol. 2004;94:92-5

14. Zhao P, Ise H, Hongo M, Ota M, Konishi I, Nikaido T. Human amniotic mesenchymal cells have some characteristics of cardiomyocytes. Transplantation 2005;79:528-35.

15. Alviano F, Fossati V, Marchionni C, Arpinati M, Bonsi L, Franchina M, et al. Term amniotic membrane is a high throughput source for multipotent mesenchymal stem cells with the ability to differentiate into endothelial cells in vitro. BMC Dev Biol. 2007;7:11.

16. Ishikane S, Ohnishi S, Yamahara K, Sada M, Harada K, Mishima K, et al. Allogeneic injection of fetal membrane-derived mesenchymal stem cells induces therapeutic angiogenesis in a rat model of hind limb ischemia. Stem Cells. 2008;26:2625-33.

17. Ishikane S, Yamahara K, Sada M, Harada K, Kodama M, IshibashiUeda $\mathrm{H}$, et al. Allogeneic administration of fetal membrane-derived mesenchymal stem cells attenuates acute myocarditis in rats. J Mol Cell Cardiol. 2010;49:753-61.

18. Tsuda H, Yamahara K, Ishikane S, Otani K, Nakamura A, Sawai K, et al. Allogenic fetal membrane-derived mesenchymal stem cells contribute to renal repair in experimental glomerulonephritis. Am J Physiol Renal Physiol. 2010;299: F1004-13.

19. Ohshima M, Yamahara K, Ishikane S, Harada K, Tsuda H, Otani K, et al. Systemic transplantation of allogenic fetal membrane-derived mesenchymal stem cells suppresses Th1 and Th17 T cell responses in experimental autoimmune myocarditis. J Mol Cell Cardiol. 2012;53:420-8.

20. Su X, Wang L, Song Y, Bai C. Inhibition of inflammatory responses by ambroxol, a mucolytic agent, in a murine model of acute lung injury induced by lipopolysaccharide. Intensive Care Med. 2004;30:133-40. 
21. Siu GD, Young AL, Cheng LL. Long-term symptomatic relief of bullous keratopathy with amniotic membrane transplant. Int Ophthalmol. 2015;35:777-83.

22. Nagato M, Okamoto K, Abe Y, Higure A, Yamaguchi K. Recombinant human soluble thrombomodulin decreases the plasma high-mobility group box-1 protein levels, whereas improving the acute liver injury and survival rates in experimental endotoxemia. Crit Care Med. 2009;37:2181-6.

23. Hagiwara S, Iwasaka H, Matsumoto S, Hasegawa A, Yasuda N, Noguchi T. In vivo and in vitro effects of the anticoagulant, thrombomodulin, on the inflammatory response in rodent models. Shock. 2010;33:282-8.

24. Wan S, LeClerc JL, Vincent JL. Inflammatory response to cardiopulmonary bypass: mechanisms involved and possible therapeutic strategies. Chest. 1997 ; 112:676-92.

25. Ng CS, Wan S, Yim AP, Arifi AA. Pulmonary dysfunction after cardiac surgery. Chest. 2002;121:1269-77.

26. Ng CS, Wan S. Limiting inflammatory response to cardiopulmonary bypass: pharmaceutical strategies. Curr Opin Pharmacol. 2012;12:155-9.

27. Masumoto H, Sakata R. Cardiovascular surgery for realization of regenerative medicine. Gen Thorac Cardiovasc Surg. 2012;60:744-55.

28. Ferraris VA. How do cells talk to each other? Paracrine factors secreted by mesenchymal stromal cells. J Thorac Cardiovasc Surg. 2016;151:849-51.

29. Hwang B, Liles WC, Waworuntu R, Mulligan MS. Pretreatment with bone marrow-derived mesenchymal stromal cell-conditioned media confers pulmonary ischemic tolerance. J Thorac Cardiovasc Surg. 2016;151:841-6.

30. Rodrigo SF, van Ramshorst J, Hoogslag GE, Boden H, Velders MA, Cannegieter SC, et al. Intramyocardial injection of autologous bone marrowderived ex vivo expanded mesenchymal stem cells in acute myocardial infarction patients is feasible and safe up to 5 years of follow-up. J Cardiovasc Transl Res. 2013;6:816-25.

31. Mathiasen AB, Qayyum AA, Jorgensen E, Helqvist S, Fischer-Nielsen A, Kofoed KF, et al. Bone marrow-derived mesenchymal stromal cell treatment in patients with severe ischaemic heart failure: a randomized placebo-controlled trial (MSC-HF trial). Eur Heart J. 2015;36:1744-53.

32. Hare JM, Fishman JE, Gerstenblith G, DiFede Velazquez DL, Zambrano JP, Suncion VY, et al. Comparison of allogeneic vs autologous bone marrowderived mesenchymal stem cells delivered by transendocardial injection in patients with ischemic cardiomyopathy: the POSEIDON randomized trial. JAMA. 2012;308:2369-79.
33. Zhao K, Lou R, Huang F, Peng Y, Jiang Z, Huang K, et al. Immunomodulation effects of mesenchymal stromal cells on acute graft-versus-host disease after hematopoietic stem cell transplantation. Biol Blood Marrow Transplant. 2015;21:97-104.

34. Forbes GM, Sturm MJ, Leong RW, Sparrow MP, Segarajasingam D, Cummins AG, et al. A phase 2 study of allogeneic mesenchymal stromal cells for luminal Crohn's disease refractory to biologic therapy. Clin Gastroenterol Hepatol. 2014;12:64-71.

35. Matthay MA, Thompson BT, Read EJ, McKenna DH Jr, Liu KD, Calfee CS, et al. Therapeutic potential of mesenchymal stem cells for severe acute lung injury. Chest. 2010;138:965-72.

36. Saito S, Nakayama T, Hashimoto N, Miyata Y, Egashira K, Nakao N, et al. Mesenchymal stem cells stably transduced with a dominant-negative inhibitor of CCL2 greatly attenuate bleomycin-induced lung damage. Am J Pathol. 2011;179:1088-94.

37. Casiraghi F, Azzollini N, Cassis P, Imberti B, Morigi M, Cugini D, et al. Pretransplant infusion of mesenchymal stem cells prolongs the survival of a semiallogeneic heart transplant through the generation of regulatory $\mathrm{T}$ cells. J Immunol. 2008;181:3933-46.

38. Araujo IM, Abreu SC, Maron-Gutierrez T, Cruz F, Fujisaki L, Carreira H Jr, et al. Bone marrow-derived mononuclear cell therapy in experimental pulmonary and extrapulmonary acute lung injury. Crit Care Med. 2010;38:1733-41.

39. Abreu SC, Antunes MA, Maron-Gutierrez T, Cruz FF, Carmo LG, Ornellas DS, et al. Effects of bone marrow-derived mononuclear cells on airway and lung parenchyma remodeling in a murine model of chronic allergic inflammation. Respir Physiol Neurobiol. 2011;175:153-63.

40. Li JW, Wu X. Mesenchymal stem cells ameliorate LPS-induced acute lung injury through KGF promoting alveolar fluid clearance of alveolar type II cells. Eur Rev Med Pharmacol Sci. 2015;19:2368-78.

41. Just N, Tillie-Leblond I, Guery BP, Fourneau C, Tonnel AB, Gosset P. Keratinocyte growth factor (KGF) decreases ICAM-1 and VCAM-1 cell expression on bronchial epithelial cells. Clin Exp Immunol. 2003;132:61-9.

Key Words: mesenchymal stem cells, cardiopulmonary bypass, systemic inflammation, acute lung injury, lung protection 